This item was submitted to Loughborough's Research Repository by the author.

Items in Figshare are protected by copyright, with all rights reserved, unless otherwise indicated.

\title{
Requirement elicitaton techniques for an improved case based lesson planning system
}

PLEASE CITE THE PUBLISHED VERSION

https://doi.org/10.1108/JSIT-12-2016-0080

PUBLISHER

Emerald

VERSION

AM (Accepted Manuscript)

\section{PUBLISHER STATEMENT}

This work is made available according to the conditions of the Creative Commons Attribution-NonCommercialNoDerivatives 4.0 International (CC BY-NC-ND 4.0) licence. Full details of this licence are available at: https://creativecommons.org/licenses/by-nc-nd/4.0/

\section{LICENCE}

CC BY-NC-ND 4.0

\section{REPOSITORY RECORD}

Dawson, Christian W., and Aslina Saad. 2019. "Requirement Elicitaton Techniques for an Improved Case Based Lesson Planning System”. figshare. https://hdl.handle.net/2134/27851. 


\section{REQUIREMENT ELICITATION TECHNIQUES FOR AN IMPROVED CASE BASED LESSON PLANNING SYSTEM}

\begin{tabular}{|r|l|}
\hline Journal: & Journal of Systems and Information Technology \\
\hline Manuscript ID & JSIT-12-2016-0080.R2 \\
\hline Manuscript Type: & Research Paper \\
\hline Keywords: & $\begin{array}{l}\text { Document review, Requirement Elicitation, Requirement analysis, Lesson } \\
\text { Plan, Interview, Survey }\end{array}$ \\
\hline \multicolumn{2}{|l}{} \\
\hline
\end{tabular}

\section{SCHOLARONE ${ }^{\text {M }}$ \\ Manuscripts}




\title{
REQUIREMENT
}

\begin{abstract}
Purpose

This paper presents a recommendation on how one requirement elicitation technique supports the other techniques in defining system requirement for a case based system. A case based lesson planning system aims to assist teachers in constructing quality lesson plans through its cycle which begins with case retrieval. In order to retrieve relevant lesson plans, appropriate inputs should be used and the intended output needs to be identified via suitable requirement elicitation techniques. The use of single technique might results in inadequate requirement specification, thus affect the quality of the output requirements as well as quality of the final information system.

Methodology

Both qualitative and quantitative approaches, using various techniques for triangulation purposes were performed in three phases. Documents were reviewed by analysing lesson plans from three different countries. In addition, a review of lesson plans prepared by teachers and the standard syllabus were carried out. Findings from the document review were used in structured interviews using a teach-back technique, sorting and matrix of attribute-values. A questionnaire was then constructed based on the interviews and document review.
\end{abstract}

Findings

The findings of this study show that various requirement elicitation (RE) techniques manage to define accurate and complete specification of software requirement. As part of a larger research investigation, it helps in system modelling and representation. This contribute to effective case retrieval via good design of the system input and output, and ultimately facilitate the development of an efficient case based lesson planning system.

Research limitation

The study intends to elicit requirements and acquire knowledge of the lesson plan domain within the Malaysian context with the aim to develop a case based lesson planning system. For the other types of information system and for different domain, different techniques might be considered.

Practical implication

Various RE techniques can be applied in different phases of requirement elicitation. Suitable technique should be chosen at different phases of RE, as it is important for triangulation purposes. Incomplete RE will affect the modeling part of system development, and thus affect the design and implementation of an information system. Software engineer or anybody involves in system development should plan accordingly for the RE process. They should be creative and reasonable in selecting suitable RE techniques to be applied

Originality/ value

The findings of this initial study, as part of a larger research investigation, would help in knowledge modelling and representation. This will contribute to effective case retrieval via good design of the system input and output. 
Keywords: Requirement elicitation, requirement analysis, document review, interview, survey, lesson

plan.

\subsection{INTRODUCTION}

Past research shows that lesson planning imposes a significant burden on teachers and causes excessive workloads amongst them. Teachers spend a lot of time on lesson planning because lesson preparation should be tailored to the constraints teachers have: students' profile, teacher's profile and facilities available. In Malaysia, teachers' overloaded workload is not a new issue. The teachers' workload issue was raised by the Malaysian National Union of teaching Profession (NUTP) in March 2010 [1]. Prior to this, the Ministry of Education in 2005 admitted that teachers' workloads had increased as they have to handle files and records and write reports besides teaching [2]. It was reported that teachers in four states in Malaysia, Selangor, Melaka, Johor and Kuala Lumpur have excessive workload; 74 hours per week compared to a maximum 48 hours, specified by International Labour Organisation (ILO) [3]. They listed five main works done by teachers other than teaching - the first task being to manage data, files and the teaching record book.

In 2008, The Education Ministry was said to give emphasis in resolving the teachers' workload issue, which is the main agenda in the second term of the Education Development Master Plan (PIPP) [4]. The Education Ministry has also set up a committee to look into complaints that teachers are being burdened with too much work. The panel includes representatives from the NUTP [5]. In June 2010, the Ministry aimed to ease teachers' workload with several suggestions [4].

Numerous suggestions have been made to help teachers in dealing with lesson plan preparation. Among the suggestions is to use other teachers' plans or to modify others' lesson plans to suit their teaching, rather than start everything from scratch which normally consumes more time. Thus, a case based system based on Case Based Reasoning (CBR) which has the capability to find relevant cases that solve similar problems to the current problem, offers solutions to lesson preparation problems among teachers. CBR comprises four main activities within it cycle which are retrieval, reuse, revise and retain. 
In $\mathrm{CBR}$, the basic processes of solving a new problem entails the retrieval of relevant cases from a memory of cases (case base) followed by the adaptation of the past solution. Given the description of a new problem, called the query case, the first, and arguably most crucial step in a CBR system is to retrieve those cases from the case base that are most relevant to solving the query case. Several aspects of lesson plans need to be investigated so that important aspects are taken into account in a tool to assist lesson preparation. Moreover, teachers' requirement of the system, and the kind of explanation that would be useful to the end users, is important to design the system.

Incomplete and incorrect requirements are single biggest cause of software project failure and therefore requirement engineering (RE) can be seen as the success-critical activity in the software development process [20]. One of the objectives of requirement engineering process is to define requirements that accurately represent users' need. This is inline with [19] who stated that the requirement elicitation phase is generally viewed as crucial to the quality of the developed system. According to Chung [6], the complexity and usefulness of large information systems are determined partly by their functionality, i.e., what they do, and partly by global constraints on their accuracy, security, cost, user-friendliness, performance, and the like.

This study aims to elicit requirements and acquire knowledge of the lesson plan domain within the Malaysian context with the aim to develop a case based lesson planning system. The gathered knowledge will be used as inputs to produce the intended output which is a lesson plan that contains all appropriate components by taking into account various constraints. This will facilitate the development of a case based lesson planning system.

Requirement elicitation aims to gain understanding of various aspects of lesson planning. Crucial knowledge in lesson planning that was gathered from the elicitation phase is modelled in order to have a good understanding of the problems and constraints among teachers. The findings of this initial study, as part of a larger research investigation, would help in knowledge modelling and representation. This will contribute to effective case retrieval via good design of the system input and output.

To guide this preliminary investigation, which intends to facilitate lesson plan retrieval, several objectives were formulated as follows: 
i. To identify components of a lesson plan.

ii. To rank the components according to their importance from a teachers' perspective

iii. To acquire relevant input that produces intended output of a lesson plan for the retrieval function.

iv. To identify the features of a good lesson planning system required by teachers.

Addressing the above research objectives entails the following research questions:

i. What components make a good lesson plan?

ii. How important are the lesson plan components for teachers in preparing lesson plans?

iii. What input is required for the intended output?

iv. What kind of (output) is needed by teachers?

v. What are the features of a good lesson planning system required by teachers?

The findings of this paper can be used by requirements engineers to gain new insights into the ways of requirement generation in their clients and to create working environments to support IS development processes, via a good start of requirement specification.

\subsection{Requirement Elicitation}

Requirements analysis is the process of determining user expectations for a new software or information system. In expert system or knowledge based systems, requirement elicitation is normally referred to knowledge acquisition. Requirements engineering is the most important phase of the software development life cycle (SDLC) [7], [8], [9], [10]. Tiwari et al. Tiwari et al. in [11] reinforces the statement that software development processes consist of many knowledge intensive processes, among which requirement elicitation is perhaps the most critical for the success of the software system.. Since requirements engineering has an important role in different stages of the SDLC, its consideration in software development is crucial. This is supported by Vásquez-Brav [12] who mentioned that the elicitation techniques provided by software engineering can improve knowledge acquisition. On one side, researchers and practitioners are cognizant of the fact that most project failures are attributed to poor requirements [13]. Software requirements are often not set in concrete at the start of a software development project [28]. The selection of requirements engineering techniques during software project development is a challenge for most developers [21]. 
The requirements elicitation process is intended to gain knowledge about the user's requirement or need [11]. The purpose of requirement engineering is to understand the problem that arises from the needs of stakeholders, including, but not limited to, customers and end-users and transform it into requirements to define and design the related solution. This means that the RE focus is about the interaction of the solution with the problem,and not the behavior of the solution itself [25]. It covers the capture and discovery of stakeholder needs. Its aim is to identify information determining what features the software system should have [10]. This phase is used to translate the imprecise, incomplete needs and wishes of the potential users of software into complete, precise and formal specifications [7]. Dante Camizo et al. [10] stated that the requirements engineering process is composed of: requirements elicitation, analysis, specification, validation and management.

There exist various techniques for requirements engineering. Software engineers can utilise a myriad of elicitation techniques to capture relevant information in order to specify requirements. The effectiveness of these techniques varies depending on the context in which the elicitation takes place [26]. Dante Camizo et al. [10] listed a variety of requirement elicitation techniques namely open ended interview, structured interview, task observation, card sorting / laddering, questionnaires, protocol analysis, repertory grid, brainstorming, Delphi technique, prototyping, focus group, JAD workshop and scenarios or use cases. However, previous research shows that software engineers tend to choose one technique over the others. [21] conclude that although there are many factors that influence the success of a project but application of combination of requirement engineering techniques was a significant factor for the successful implementation of this project with higher requirements volatility.

Software engineers tend to choose a technique to apply on one of the following grounds [14] in [10]: it is the only technique they are acquainted with; it is their favorite technique for all situations; they are using a methodology that prescribes a particular technique; or they guess that the technique is effective under existing circumstances. This subjective decision can bias the elicitation results, degrade the quality of the output requirements and ultimately, have an impact on the quality of the final software product [9]. According to Kaulio and Marianne [15], there is evidence, that traditional interviews are inadequate for the development of systems today. Popular notations for functional requirements specifications frequently ignore developers' 
needs, target specific development models, or require translation of requirements into tests for verification; the results can give out-of-sync or downright incompatible artifacts [27].

Therefore, various techniques should be applied in triangulation to support requirements determination. Kaulio and Marianne [15] stated that the concept of triangulation is introduced as a 'conceptual tool' for managing the multidimensionality of user requirements investigations. This is inline with Mishra, yaziki and Mishra [20]. In some complex problems, combination of requirement engineering techniques should be applied for efficient and successful requirement engineering process [21]. Also, in this ever evolving world, it is impossible to know all the requirements before construction begins. The development of requirements specifications is conceived as an incremental process, in which the stakeholders successively add requirements until getting to the specifications of the desired system [23]. Therefore, we should try to define as many requirements as we can before the development begins, but it is not always possible to know everything initially.

According to [21], the significance of choosing the proper techniques and models during software development has already been emphasized by numerous researchers and practitioners. [21] quotes [22] that it has been established that applying the right technique to a given problem is necessary for effective requirement analysis. Furthermore, [21] cited [23] where there is also a need to apply combination of requirement elicitation techniques based on project characteristics. The merit of using a combination of requirement elicitation techniques is that a specialized technique that is highly effective in addressing a particular problem can be complemented with other techniques that deal with issues that the former techniques do not address. This will help in developing high quality requirements for software projects.

The remainder of this paper is structured as follows. Section 2 presents the methodology of the study. Section 3 covers the results and discussion before the paper ends with conclusions in section 4 .

\subsection{METHODOLOGY}


This research used both qualitative and quantitative approaches to answer the research questions, which involved semi-structured interviews, document review and survey to collect the relevant data. Figure 1 shows techniques applied for requirements elicitation and their outcome which is important in case retrieval.

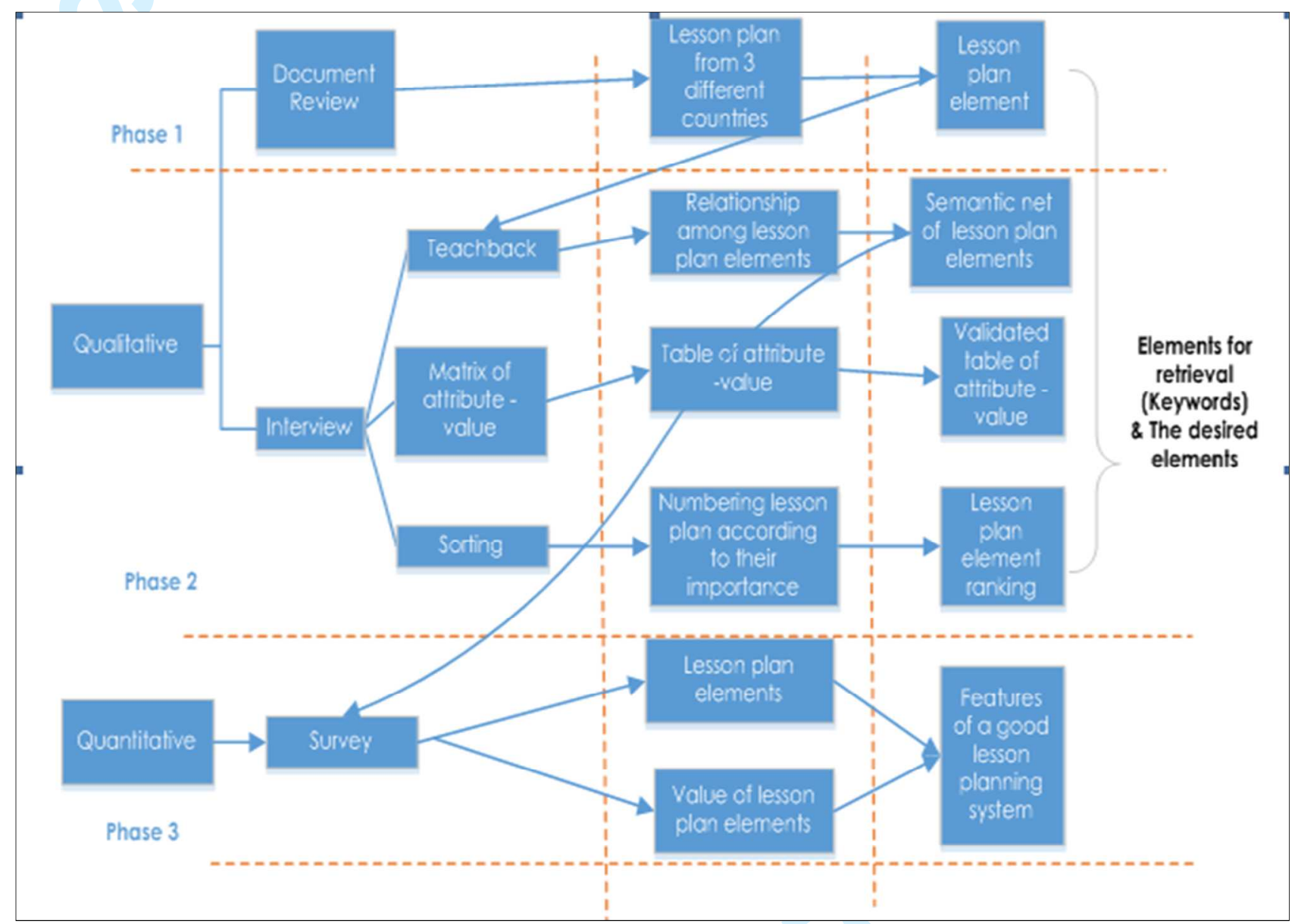

Figure 1 : Various techniques applied for requirement elicitation

As the case based lesson planning system is developed for Malaysian schools environment, the techniques that were applied suit the school environment and involves stakeholders for the context of schools in Malaysia. For qualitative methods, interview sessions, which included a teach-back technique, sorting and matrix of attributes-value were performed with teachers who teach Science and Mathematics subjects from five secondary schools. In addition, previous lesson plans, which were prepared by teachers, were also reviewed. For quantitative methods, surveys were conducted using Google form. Official permission was acquired from the State Education Department in order to meet the school teachers for research purposes. Prior to this, the Malaysian Economic Planning Unit (EPU) and Malaysian 
Research Department were informed about the research by providing all details of the researcher and research. The schools' management were then contacted to get information about the teachers who teach the two subjects. The teachers are contacted and meetings with teachers from the same schools were arranged. In the meeting, the whole research processes was discussed and explained to participants.

Knowledge elicitation was carried out in several phases: phase I involved document review, phase II was an interview and phase III used a survey. Respondents of the study comprised experienced teachers as well as new teachers.

\section{Phase I: Document review}

Documents relating to lesson plans were gathered from teachers and online resources. The curriculum syllabus was obtained from the Ministry of Education portal which is referred by all teachers in planning their teaching. It contains almost all of the important information in constructing lesson plans such as learning outcomes to be achieved and time period of a particular learning area. In addition, lesson plans from the UK, the US and Malaysia were analysed and compared to each other.

\section{Phase 2: Interview (with Teach Back)}

The interviews using teach-back technique aimed to elicit important knowledge regarding lesson preparation by 15 experienced teachers. The teach-back technique was carried out in parallel to the interviews. In this technique, the researcher elicits knowledge from the teachers by mutual reference to diagrams on paper. A comparison table of Malaysian, British and American components of lesson plans were showed to teachers to determine whether they agreed with that or not. In addition, part of the knowledge that was acquired during previous sessions with other teachers was described to the respective respondents. Lesson plan books were also shown to teachers to gain feedback regarding important components in a lesson plan.

In a matrix-based technique, attributes and values for elements in a lesson plan domain were presented to teachers. They then commented whether the pairs of attributes and values were correct. A sorting technique was applied in ranking the elements in lesson plans according to 
their importance for lesson plan searching. Prior to this, a graph showing how elements in a lesson plan relate to each other was presented to teachers to get feedback and comment from them.

\section{Phase 3: Survey}

Questionnaires were distributed to 25 secondary school teachers after handling all other fact finding techniques. The results from interview sessions and document review were then used as a basis for the questionnaire. The survey aimed to identify teachers' constraints and factors that influence them in selecting particular elements in lesson planning. In addition, it intended to obtain teachers' input towards preparing lesson plans and whether it could be improved upon by implementing an online case based lesson planning system. The respondents were asked which components (keywords) of lesson plans they prefer to use while searching for related lesson plans. Teachers' requirements for the system and their expectation towards an online lesson planning system was crucial in order to develop a computer assisted system which helps them in preparing lesson plans. The questionnaires were analysed using SPSS. The expected deliverables are knowledge in the lesson plan domain; components in a lesson plan, lesson planning sequence and the importance of each component in lesson. User requirements of the new system were elicited from the results.

\subsection{RESULTS AND DISCUSSION}

The main goal of the systems analysis is to specify complete and detailed requirements of the proposed case based lesson planning system. Although there are two main types of requirement; functional and non-functional requirements, this paper only focus on functional requirements specifically case retrieval with input and output. The deliverable from the knowledge analysis process is all the main concepts in the lesson plans domain with their details. This is crucial to assure that all related knowledge in lesson planning is modeled appropriately and implemented accordingly in the system. 
This section presents results based on the listed questions in the introduction. It starts with important components of a lesson plan. The rank of lesson plan components according to their importance from teachers' perspective is presented in the following section. This is important to acquire relevant input (keywords) that produced intended output of a lesson plan. Features of a case-based lesson planning system are discussed in last section before the conclusions.

\subsection{Elements of a lesson plan}

Table 1 presents the analysed components of a lesson plan in Malaysian (M), UK and the US acquired from the portal of the education department of each country. The table lists the example and meaning of the components, the currently available components, and components that are available in other lesson plans which can possibly be added in the Malaysian context. It shows some of the similarities and differences in lesson plan elements from Malaysian, British and American lesson plans.

Although there are some variations in standardized lesson plan formats by education departments from different countries, they principally have the same components. The three nations all have subjects, topics, objectives and planned contents in their standard plan format. Resources used for a specific class and year are also taken into account by all three. This indicates that they are the main components in a lesson plan. For the British lesson plan, lesson outline is detailed in an additional column (visual, auditory and kinesthetic column) while American and Malaysian lesson plans require teachers to specify activities and techniques. Time allotted, timing of each activity, room and assessment on the topic being taught are both considered in the British and Malaysian lesson plans. However, the Malaysian and American lesson plan formats require teachers to identify prerequisite knowledge.

Short lesson description, curriculum standards met in the lesson, classroom layout and grouping of students are identified in lesson plans prepared by American teachers. Requirements for special learners are also taken into account by American teachers. Closure, the last activity in a teaching session, is specified by Malaysian teachers whilst both American and British consider extending the lesson in terms of homework. Although there are some differences in the 
Table 1 : Components of a lesson plan in Malaysian context

\begin{tabular}{|c|c|c|c|c|c|}
\hline No & Items & Meaning/ example & US & UK & $\mathbf{M}$ \\
\hline 1 & Subject & ICT, Science, History & $\sqrt{ }$ & $\sqrt{ }$ & $\sqrt{ }$ \\
\hline 2 & Topic & Computer System & $\sqrt{ }$ & $\sqrt{ }$ & $\sqrt{ }$ \\
\hline 3 & Lesson author & The name of the teacher & $\sqrt{ }$ & & \\
\hline 4 & Year/class & Form 1, form 4 & $\sqrt{ }$ & $\sqrt{ }$ & $\sqrt{ }$ \\
\hline 5 & No of pupils & $23,25,30,35,40$ & & $\sqrt{ }$ & $\sqrt{ }$ \\
\hline 6 & Skills & Communications, Information management & & 2 & $\sqrt{ }$ \\
\hline 7 & $\begin{array}{l}\text { Scientific attitude \& } \\
\text { moral value }\end{array}$ & Confidence, responsibility, integrity. & & & $\sqrt{ }$ \\
\hline 8 & Ability range & $\begin{array}{l}\text { (Level of students) } \\
\text { Excellent, average }\end{array}$ & & $\sqrt{ }$ & \\
\hline \multirow[t]{2}{*}{9} & Gender & Male/ Female & & $\sqrt{ }$ & 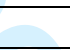 \\
\hline & Teaching aids & $\begin{array}{l}\text { Hardware.ppt, } \\
\text { Exercise1.doc }\end{array}$ & & & \\
\hline 10 & Time allotted & 60 minutes, & & $\sqrt{ }$ & $\sqrt{ }$ \\
\hline 11 & Room & Computer lab, classroom & & $\sqrt{ }$ & $\sqrt{ }$ \\
\hline 12 & $\begin{array}{l}\text { Short description of } \\
\text { lesson }\end{array}$ & Brief explanation of overall lesson. & $\sqrt{ }$ & & \\
\hline 13 & Resources & Computer, printer, scanner & $\sqrt{ }$ & $\sqrt{ }$ & $\sqrt{ }$ \\
\hline
\end{tabular}

The analysed components were then presented to Malaysian teachers to validate the findings using the teach-back technique. The criteria for a quality lesson plan were identified. A good lesson plan is further characterized by the presence of all the important components. The study found that a good lesson plan should include the following 12 components: objectives, time constraint, introduction, learning activity, enrichment, assessment, closure, prerequisites, reward, content, material (teaching aids) and resources.

The study also demonstrates that Malaysian teachers apply Bloom's taxonomy model in constructing daily lessons and Gagne's nine commandments to plan the learning steps [16]. The six levels in Bloom's taxonomy within the cognitive domain, together with the activities in ascending order, are knowledge (recall), comprehension (understanding), application (use, practice), analysis (dissection, generalization), synthesis (creating, combining) and evaluation (appraising, valuing). Gagne's nine events that activate processes needed for effective learning should include this sequence of events; gain attention, inform learner of objective, stimulate recall of prior knowledge, present the material, provide guidance for learning, elicit performance, provide feedback. 


\begin{tabular}{|c|c|c|c|c|c|}
\hline 14 & Pre requisite skill & $\begin{array}{l}\text { A statement of what a student needs to know } \\
\text { or be able to do to succeed and accomplish the } \\
\text { lesson objective. }\end{array}$ & $\sqrt{ }$ & & $\sqrt{ }$ \\
\hline 15 & $\begin{array}{l}\text { Classroom layout and } \\
\text { Grouping of students }\end{array}$ & The arrangement of furniture, learning style. & $\sqrt{ }$ & & \\
\hline 16 & Objectives & $\begin{array}{l}\text { A more specific and can be behavioral } \\
\text { or non- behavioral. }\end{array}$ & $\begin{array}{c}\sqrt{ } \\
\text { Instructional } \\
\text { objectives }\end{array}$ & $\begin{array}{c}\text { L } \\
\text { Literacy \& } \\
\text { Behavior } \\
\text { objectives }\end{array}$ & $\sqrt{ }$ \\
\hline 17 & Outcomes & $\begin{array}{l}\text { What should be achieved by the end of } \\
\text { Lesson }\end{array}$ & & $\begin{array}{l}\text { Literacy \& } \\
\text { Behavior } \\
\text { outcome }\end{array}$ & \\
\hline 18 & $\begin{array}{l}\text { Timing of each } \\
\text { activity }\end{array}$ & $\begin{array}{l}5 \text { minutes }(9.00-9.05 \mathrm{am}) \\
10-15 \text { minutes }(8.10-8.25 \mathrm{am})\end{array}$ & & $\sqrt{ }$ & $\sqrt{ }$ \\
\hline 19 & Induction set & Introduction & & & $\sqrt{ }$ \\
\hline 20 & $\begin{array}{l}\text { Planned } \\
\text { Content/lesson } \\
\text { outline }\end{array}$ & Outline for each step in lesson plans & $\begin{array}{l}\text { V } \\
\text { (technique \& } \\
\text { activities) }\end{array}$ & $\begin{array}{c}\sqrt{ } \\
\text { (plus } \\
\text { VAK) }\end{array}$ & $\sqrt{ }$ \\
\hline 21 & $\begin{array}{ll}\text { Adaptation } & \text { for } \\
\text { special learners }\end{array}$ & $\begin{array}{l}\text { Extended time for certain students in carrying } \\
\text { out activity. } \\
\text { Different approach in carry out learning } \\
\text { activities. }\end{array}$ & $\sqrt{ }$ & & \\
\hline 22 & Enrichment & $\begin{array}{l}\text { Activity to reinforce students' understanding } \\
\text { of what each objective stated }\end{array}$ & & $\sqrt{ }$ & \\
\hline 23 & Student products & Scrap book & $\sqrt{ }$ & & \\
\hline 24 & Assessment & $\begin{array}{l}\text { Exercises, quizzes etc, by the end of lesson to } \\
\text { measure students' understanding. }\end{array}$ & & $\sqrt{ }$ & $\sqrt{ }$ \\
\hline \multirow[t]{2}{*}{25} & $\begin{array}{l}\text { Extension/ } \\
\text { Homework }\end{array}$ & To reinforce what has been learnt in the class & $\sqrt{ }$ & $\sqrt{ }$ & \\
\hline & Closure & $\begin{array}{l}\text { summation of the lesson and how it relates to } \\
\text { future lessons }\end{array}$ & & & \\
\hline 26 & Reflection & $\begin{array}{l}\text { reflect on what has happened in the class as it } \\
\text { will help teachers to plan for the next lesson }\end{array}$ & & & $\sqrt{ }$ \\
\hline
\end{tabular}

\subsection{Ranking of the Lesson Plan Elements, Relevant Input and Intended Output}

As explained in the previous section; knowledge acquisition was undertaken in three phases. In the first phase, all important elements were gathered from documents reviewed. The lesson plan components were analysed as shown in Table 1. Then, in the second phase, these components were presented to teachers to seek for their confirmation.

The concept of a case in CBR which comprised two major parts- problem (situation description) and their pair solution was explained to the teachers. After discussion with teachers, components of a lesson plan were divided into two; components for retrieval (keywords) and the desired content (output). However, at this stage those components were not listed in ranking. 
A survey was distributed to 25 teachers who taught various subjects in Malaysian secondary schools. A total of $80 \%$ of them were between 20 and 30 years old with less than 5 years' experience. There were $12 \%$ between 31 and 40, and 8\% between 41 and 50. The respondents need to select which keywords they preferred to use in order to obtain the desired components in their lesson plans. They were also required to select the most wanted output from their specified keywords.

Table 2 shows the ranked lesson plan components according to users' preference when searching for related lesson materials. It also presents the input (keyword) that is normally used by teachers to search for related lesson plans. Next to the input is the output expected by teachers when they search for lesson plans.

These facts are important to determine the weighting of each element applied to get the most relevant cases in the retrieval process. The top ranking components in Table 2 are used in the user interface of the searching function as teachers prefer to gather some components over others when preparing lesson plans.

Table 2 : Ranked lesson plans elements and the content

\begin{tabular}{|c|l|l|}
\hline No & Elements for retrieval & The desired content \\
\hline 1 & Learning Outcomes & Resources/ material \\
\hline 2 & Topic & Short Description \\
\hline 3 & Learning Area & Learning activities \\
\hline 4 & Students ability & Learning objectives \\
\hline 5 & Students' previous knowledge & Introduction \\
\hline 6 & No of students in class & Enrichment \\
\hline 7 & Time period & Assessment \\
\hline 8 & Year & Closure \\
\hline 9 & Subject & Reward \\
\hline 10 & Skills & \\
\hline 11 & Attitude/ value & \\
\hline 12 & Students' motivation & \\
\hline
\end{tabular}

Table 2 shows that learning outcome is ranked higher than other components for retrieval. Teachers are more interested in the learning outcome than the learning areas and topics, because it is more specific to the searched content. Out of 25 respondents, $68 \%$ preferred to search the learning outcome as 
opposed to topic $(64 \%)$ and learning area $(60 \%)$. On the other hand, learning objectives are defined by teachers based on the learning outcome, students' ability, and students' previous knowledge.

More than half of the respondents (76\%) stated that reflection is a vital element in lesson plans as it feeds into the next class. This also indicates the importance of a case-based reasoning system in which previously implemented lesson plans are referred to by teachers when constructing a new lesson plan. Teachers can also learn from reflection written by other teachers. All important components in the lesson plan domain were identified during the knowledge acquisition process.

The results from the requirement elicitation or knowledge acquisition phase revealed lesson plan components in rank, according to users' consideration for case retrieval. It starts with learning outcomes, followed by topic, learning area, students' ability, students' previous knowledge, the number of students in the class, time period, year, subject, skills, attitude/value and students' motivation. The components that teachers prefer to search in constructing lesson plans were considered. Also discussed were the keywords that they prefer to use to get the desired components in lesson plans. These facts are important in determining the weight of each element in term weighting, which is applied to get the most similar cases in the retrieval process. The respondents were also asked what components of lesson plans they would like to get while searching. The results are listed and ranked as follows: resources/materials, short description, learning activities, learning objectives, introduction, enrichment, assessment, closure and reward.

Good lesson planning is essential for any systematic approach to instruction. Although many teachers become discouraged by the time required to plan, a well written and properly used lesson plan can be a highly worthwhile teaching aid. Experienced teachers use written lesson plans for a variety of purposes. They can be checkpoints to ensure well-planned learning experiences. They can serve as teaching guides during lessons and as references for other instructors who may have to teach a lesson with very short notice. They also serve as convenient records of an instructor's planning techniques and methods of teaching. One of the most practical functions of lesson plans is that they serve as step-bystep guides for instructors in developing teaching and learning activities. Kizlik [17] indicates that when teachers are learning the craft of teaching, organizing their subject-matter content via lesson plans is fundamentally important. Besides, the first teaching work specified by the US government is to plan and prepare lessons and courses for pupils followed by delivering lessons to pupils [18]. 


\subsection{Features of a Good Lesson Planning System Required by Teachers}

In order to implement a system that assists teachers in lesson planning, the required features of the system were gathered. The analysed results from a survey shows that $96 \%$ of 25 respondents have a positive attitude towards web-based systems for lesson plan construction and look forward to using it. The respondents also implied that a lesson planning system that manages to retrieve previously implemented lesson plans and teaching materials is more valuable to teachers than a system which merely explains how to integrate technology in teaching, as offered by some online lesson planning systems.

Furthermore, the system should be dynamic, whereby the users can interact and change the elements of the retrieved lesson plans, not only view and print them. As a web-based system is required, the system should be made available on a $24 / 7$ basis. In addition, this case based system should allow users, not only to retrieve previous implemented lesson plans by other teachers on the Internet, but also to generate their own lesson plans based on old cases with access to all related materials and teaching aids.

Teachers were given some choices of the final output from the lesson planning system that would assist them in constructing lesson plans such as videos about successfully implemented lesson plans, stories about how teachers implement the lesson plans and a text-based format (current style in manual process). The text-based format of successfully implemented lesson plans leads the rest, which was preferred by $64 \%$ of the respondents.

\subsection{CONCLUSION}

The requirements elicitation process is critical in information systems development as a complete requirements specification is essential to fulfill the users' need towards the system. For a case based lesson planning system, triangulation strategies have been applied in user requirements investigation. Document review, interview and survey were carried out in three phases.

Although there are many more techniques exist to perform the requirement gathering process, these three techniques manage to answer the listed research question effectively in terms of cost and time. 
Besides, these requirement elicitation techniques have been used for long time, tested and proven. Triangulation facilitates validation of data through cross verification from three sources as it tests the consistency of findings from each phase. In addition, output of one technique can provide meaningful information for other techniques.

Every technique applied in this research has its strength. Document reviews are carried out early on the data gathering process, before other data collection has taken place. It provides baseline information and key issues regarding lesson planning in Malaysia. Interview involves limited number of respondents but the gathered information is more depth. Survey is one of the methods which cost less and involves many respondents compared to the other techniques. Besides, the respondents can answer the survey at their 'own' time.

Via requirement elicitation process, all aspects related to lesson plan construction were investigated to identify input, process and output required in the constructed system. The findings in the lesson planning domain, including the main concepts and important elements for lesson plan retrieval have been described. The inputs gathered from this investigation help in specifying complete and detailed requirements of the retrieval function in the proposed system. The gathered knowledge is used to construct a knowledge model of the lesson plan domain, constructing a knowledge base of teachers' experience in lesson plan preparation as it is a valuable component of a CBR system - particularly in building cases after defining its component and organising knowledge through representation.

\section{References}

[1] Mohd Dom, A. 2010. Isu Beban Tugas Guru. Putraya, October 20, 2010. Media Statement.

[2] Corporate Communication Unit, Malaysian Ministry of Education. 2010, June 20. Ministry Plans to Ease Teachers Workload. The Star. Retrieved from http://thestar.com.my/news/story.asp?sec $=$ focus \&file $=/ 2010 / 6 / 20 /$ focus $/ 6492140$

[3] Sharuddin, Z., and Rahim, N. S. 2005. Beban Kerja Guru 74 jam seminggu. Retrieved from http://www.mypendidik.net/portal/modules.php?name=News\&file=article\&sid=229

[4] Corporate Communication Unit, Malaysian Ministry of Education. 2010, June 20. Ministry Plans to Ease Teachers Workload. The Star. Retrieved from http://thestar.com.my/news/story.asp?sec=focus\&file=/2010/6/20/focus/6492140. 
[5] Vasudevan. 2010. Panel to Look into Teachers' Workload. The New Straits Times. Retrieved from http://findarticles.com/p/news-articles/new-straitstimes/mi_8016/is_20100401/panel-teachersworkload/ai n52985494/

[6] Chung, L. 1991. Representation and Utilization of Non-Functional Requirements for Information System Design. Lecture Notes in Computer Science, 498, 5-30, DOI: 10.1007/3-540-54059-8_78.

[7] Chakraborty, A., Baowaly, M. K., Arefin, A., and Bahar, A. N. 2012. The Role of Requirement Engineering in Software Development Life Cycle. Journal of Emerging Trends in Computing and Information Sciences, 3(5).

[8] Kidd, A. L. 1987. Knowledge Acquisition for Expert Systems: A Practical Handbook. Plenum Press, England, 1987.

[9] Sharma, S., and Pandey, S.K. 2013. Revisiting Requirements Elicitation Technique. International Journal of Computer Applications, 75(12), 0975 - 8887.

[10] Dante Carrizo, D., Dieste, O., and Juristo, N. 2014. Information and Software Technology Systematizing requirements elicitation technique selection. Information and Software Technology, $56(6)$.

[11] Tiwari, S., Rathore, S., and Gupta, A. 2012. Selecting Requirement Elicitation Techniques for Software Projects. Software Engineering (CONSEG), 2012 CSI Sixth International Conference (pp. 1-10), IEEE.

[12] Vásquez-Brav, D.M., Sánchez-Segura M.I., Domínguez, F. M., and Amescua, A. 2014. Knowledge Management Acquisition Improvement by Using Software Engineering Elicitation Techniques. Computers in Human Behavior, 30, 721-730.

[13] Sethia, N. K., and Pillai, A. S. 2013. The Effects of Requirements Elicitation Issues on Software Project Performance: An Empirical Analysis. Lecture Notes in Computer Science, 8396, 285-300.

[14] Davis, A., and Hickey, A. 2003. Requirements Elicitation And Requirements Elicitation Technique Selection: A Model Of Two Knowledge-Intensive Software Development Processes. Proceeding of the 36th Hawaii International Conference on System Sciences. IEEE Computer Society Press, Los Alamitos, California.

[15] Kaulio, M. A., and Marianne, K. I. C. 1998. Triangulation strategies in user requirements investigations: a case study on the development of an IT-mediated service. Behaviour \& Information Technology, 17(2).

[16] Saad, A. 2011. A Case-Based System for Lesson Plan Construction. Doctoral Thesis, Loughborough University. 
[17] Kizlik, B. 2008. Lesson Planning, Lesson Plan Formats and Lesson Plan Ideas. Retrieved May 8, 2008 from: http://www.adprima.com/lesson.htm.

[18] John, P.D. 1993. Lesson Planning for Teachers. Casselle Educational Limited. London.

[19] Thanasankit, T. 2002. Requirements engineering-exploring the influence of power and Thai values. European Journal of Information Systems, 11(2), 128-141.

[20] Cybulskia, J., Nguyenb, L., Thanasankitc, T. and Lichtenstein, S. 2003. Understanding Problem Solving in Requirements Engineering: Debating Creativity with IS Practitioners. 7th Pacific Asia Conference on Information Systems, 10-13 July 2003, Adelaide, South Australia.

[21] Mishra, D., Mishra, A. and Yazici, A. 2008. Successful requirement elicitation by combining requirement engineering techniques. Applications of Digital Information and Web Technologies Conference. ICADIWT 2008.

[22] Alan, D.M. 1993. Software Requirements, Objects, Functions and States. Prentice Hall, 1993.

[23] Jiang L., Eberlein A., and Far B.F.2005. Combining Requirements Engineering Techniques Theory and Case study. Proceeding of the 12th IEEE International Conference and Workshops on the Engineering of Computer-Based Systems (ECBS’05), 2005.

[24] Lopez-Nores M., Pazos-Arias J., Garcia-Duque J. and Barragans-Martinez B. (2006). "An agile approach to support Incremental Development of Requirements Specifications", Proceeding of the 2006 Australian Software Engineering Conference (ASWEC'06), 2006.

[25] Stefan, W., Sara, N., Thoben, K.D. (2017). Integrating requirements engineering for different domains in system development - lessons learnt from industrial SME cases. The 9th CIRP IPSS Conference: Circular Perspectives on Product/Service-System. Procedia CIRP 64, 351 - 356.

[26] Carrizo, D., Dieste,O, Juristo, N. (2017). Contextual attributes impacting the effectiveness of requirements elicitation Techniques: Mapping theoretical and empirical research. Information and Software Technology. 92(194-221). 
[27] Naumchev, A, Meyer, B. (2017). Seamless requirements. Computer Languages, Systems \& Structures 49, 119-132.

[28] Jayatilleke, S., Lai, R. (2018). A systematic review of requirements change management Information and Software Technology 93, 163-185 